\title{
CORTESIA E TRABALHO DE FACES EM PORTAIS DE NOTÍCIAS BRASILEIROS: UMA ANÁLISE DA COBERTURA DA CONDENAÇÃO DO EX-PRESIDENTE LULA
}

\author{
(Courtesy and facework in Brazilian News portals: \\ an analysis of coverage of former president Lula's condemnation)
}

\author{
Davi Rebouças ${ }^{1}$ \\ Universidade Federal Fluminense
}

\begin{abstract}
RESUMO
Investigamos, à luz da proposta de Trabalho de Faces e da Teoria da Polidez, como os portais de notícias G1, Folha de S. Paulo e CartaCapital desenvolvem marcas linguístico-discursivas desse trabalho na cobertura da condenação do ex-presidente Lula por corrupção. Por meio de análise semântico-pragmática dos atos de fala marcados por cortesia e descortesia, utilizamos atenuação e intensificação como categorias analíticas. Constatamos que os textos são marcados por traços que revelam posicionamentos e atenção dos veículos às suas próprias Faces Institucionais, conceito que defendemos aqui, em releitura à proposta goffmaniana, e que o uso das estratégias guarda relação com fatores econômico-financeiros.
\end{abstract}

Palavras-chave: (Des)Cortesia. Trabalho de Faces. Atenuação. Intensificação. Notícia de Corrupção.

\begin{abstract}
We investigated, considering the facework proposal and the politeness theory, how G1, Folha de S. Paulo and CartaCapital news portals develop linguistic-discursive marks of that work in the coverage of former President Lula's conviction of corruption. Through semantic-pragmatic analysis of speech acts marked by courtesy and discourtesy, we use attenuation and intensification as analytical categories. We note that the texts are marked by features that reveal the positioning and attention of vehicles to their own Institutional Faces, a concept that we defend here, in rereading the Goffmanian proposal, and that the use of strategies is related to economic and financial factors.
\end{abstract}

Keywords: (Dis)Courtesy. Facework. Mitigation. Intensification. Corruption News.

\section{RESUMEN}

Investigamos, considerando la propuesta de Trabajo de Fachada de Goffman y la teoría de la cortesía, cómo los portales de noticias G1, Folha de S. Paulo y CartaCapital desarrollan marcas lingüístico-discursivas de ese trabajo en la cobertura de la condena del expresidente Lula por corrupción. A través del análisis semánticopragmático de los actos del habla marcados por cortesía y descortesía, utilizamos la atenuación y la intensificación como categorías analíticas. Observamos que los textos están marcados por características que revelan el posicionamiento y la atención de los vehículos a sus propias Fachadas Institucionales, concepto que defendemos aquí, al releer la propuesta de Goffman, y que el uso de estrategias está relacionado con los factores económico y financieros.

Palabras-clave: (Des)Cortesía. Trabajo de Fachada. Atenuación. Intensificación. Noticias de corrupción.

Recebido em: dezembro 2019

Aceito em: dezembro 2019

DOI: $10.26512 /$ les.v20i3.28634

\footnotetext{
${ }^{1}$ Doutorando em Mídia e Cotidiano pela Universidade Federal Fluminense (PPGMC/UFF). Mestre em Linguística Aplicada (UECE) e membro do Grupo de Estudos sobre Preconceito, Polidez e Impolidez Linguística (UNILAB), do Grupo de Estudos GELP - COLIN (Cognição e Linguística) (UFC) e do Centro de Pesquisa e Produção em Comunicação e Emergência (UFF). E-mail: davi.mreboucas@gmail.com.
} 


\section{INTRODUÇÃO}

Sendo a cortesia uma das formas de atenuar e evitar conflitos comunicacionais, ela pode se evidenciar em diversos textos, não apenas orais ou em interações face a face. Pretendendo investigar o fenômeno em questão na cobertura jornalística sobre corrupção em portais de notícia da internet, a fim de contribuir, inicialmente, para uma melhor compreensão do fenômeno da polidez ${ }^{2}$ no cenário midiático brasileiro, principalmente em textos escritos.

A partir de uma perspectiva interdisciplinar, este trabalho, que é recorte de uma pesquisa mais ampla, investiga, à luz da proposta de Trabalho de Faces de Goffman e da Teoria da Polidez, como os profissionais do jornalismo, em textos jornalísticos como a reportagem, desenvolvem as marcas linguístico-discursivas do trabalho com as faces dos sujeitos noticiados sobre corrupção em três portais de notícias na internet (G1, Folha de S. Paulo e CartaCapital), valendo-se dos recursos de atenuação e de intensificação como estratégia, na concepção de textos mais polidos/corteses. Fazemos isso por meio de uma análise semântico-pragmática da cobertura sobre a condenação do ex-presidente Lula por crime de corrupção no caso de um apartamento triplex no Guarujá-SP.

Assim, este recorte está dividido em seções que apresentam fundamentos históricos e novas perspectivas acerca da cortesia/polidez e do trabalho de faces. Seguimos com releituras acerca desses conceitos, recontextualizando-os em diferentes possibilidades de aplicação, além das interações face a face. Antes de nosso olhar analítico, lançamos luz sobre as categorias pragmáticas da atenuação e da intensificação, que avaliamos como essenciais tanto à cortesia como ao trabalho de faces.

\section{Algumas CONSIDERAÇÕES SOBRE A CORTESIA E O TRABALHO COM AS FACES}

As investigações teóricas sobre a cortesia surgiram nas obras de Lakoff (1973) e de Leech (1983), que seguem os apontamentos de Grice (1982) de que a comunicação é um processo (dinâmico) cooperativo, guiado por máximas conversacionais, quando em uma situação ideal. Para Grice, as trocas conversacionais são regidas por uma cooperação entre os envolvidos, que reconhecem os objetivos na/da interação. Tais objetivos podem ser definidos ou indefinidos, como em uma conversa casual. Entendendo os objetivos de uma conversa, torna-se mais claro identificar enunciados inadequados à interação.

Partindo dessa ideia, Grice sugere a existência de um Princípio de Cooperação, segundo o qual as pessoas, conscientes dos objetivos da conversa, devem fornecer uma contribuição que seja suficiente, relevante, verdadeira, clara, apropriada e aceita na interação. A partir dessas características, Grice aponta

\footnotetext{
${ }^{2}$ Neste estudo, "polidez" e "cortesia" são tidas como sinônimos. A variação entre os termos é utilizada para conferir mais fluidez ao texto e para respeitar o termo adotado pelas autoras e autores citados.
} 
a existência de quatro categorias que compõem o Princípio da Cooperação e que ele denomina máximas: Máxima da Quantidade, da Qualidade, da Relação e do Modo.

Como as regras de um jogo, porém, as máximas podem ser seguidas ou violadas. No jogo da conversação, os participantes podem emitir enunciados que rompam os sentidos estritos das palavras e revelar implícitos nos ditos, que o autor denomina implicatura. Trata-se dos significados inferidos pelo interlocutor, não ditos literalmente pelo locutor. É nesse contexto, segundo Paiva, Moreira e Santos (2016), que teóricos como Leech passam a investigar o porquê de os falantes optarem por uma implicatura ao invés de serem literais, seguindo as máximas conversacionais propostas por Grice.

Leech (1983) entende que os interlocutores, ao interagirem, buscam alcançar seus objetivos atentos às máximas propostas por Grice e buscam desenvolver "bons comportamentos comunicativos", seguindo Princípios e Máximas de Polidez focalizados nos Outros, que são os interlocutores e outras pessoas que podem ser afetadas pelos enunciados (como é o caso de notícias, que podem afetar tanto o sujeito noticiado como os leitores). Somados aos impactos que a interação pode causar em um terceiro, discutidos por Leech, defendemos que múltiplos aspectos devem ser considerados ao se categorizar uma enunciação como cortês ou descortês. O enunciado, como produto, não é o único ponto que devemos considerar em tal avaliação, pois a constituição da cortesia e da descortesia é processual e está ligada às noções sócio-cognitivo-culturais. Brown e Levinson (1987) nos apontam, a partir de Goffman, três aspectos a se considerarem na avaliação da polidez em uma interação: distância social, poder e força do ato. Acreditamos ser relevante acrescentar os aspectos culturais, o meio em que a interação acontece, que pode não ser face a face, os significados que podem ser evocados pelas escolhas lexicais, os gestos, dentre outros aspectos mais particulares de cada interação, de cada enunciador.

Os autores partem das considerações sobre o Trabalho de Faces de Goffman, da teoria dos Atos de Fala de Austin - a partir de Searle (2002) - e do Princípio de Cooperação de Grice. Em sua teoria, Brown e Levinson têm o entendimento de que, em geral, os participantes de uma interação cooperam para manter as faces uns dos outros, devido a sua vulnerabilidade. Goffman já apontava que o trabalho de manutenção das faces é mútuo, pois todos buscam preservar a sua (com atitudes defensivas) e a dos outros (com atitudes protetoras). Em uma perspectiva semelhante à de Leech (1983), os autores investigam como a realização de atos de fala indiretos podem representar um ato cortês.

Segundo Goffman (2012, p. 13), face é um "valor social positivo que uma pessoa efetivamente reivindica para si mesma através da linha que os outros pressupõem que ela assumiu durante um contato particular", ou seja, pensando no que os outros pensam dela, a pessoa reivindica para si, na interação, valores sociais positivos. Podemos dizer, então, que a face é uma imagem do eu formada a partir de predicados tidos socialmente como positivos, constituída por meio de padrão de atos verbais e não verbais, seguidos pela pessoa para expressar a avaliação que ela faz dos participantes da interação, 
incluindo, principalmente, ela mesma (GOFFMAN, 2012). Face seria, pois, a imagem que se almeja tornar pública. Regras e valores sociais, assim como aspectos específicos do momento da interação, então, são fundamentais na compreensão da "composição" das imagens dos sujeitos. Determinado comportamento é esperado de um jornalista como profissional (que pertence à comunidade social de jornalistas) e como indivíduo inserido em uma situação específica de comunicação.

Contudo, para Brown e Levinson, não há apenas uma face, composta por valores positivos, mas sim duas, uma positiva e outra negativa. A positiva é semelhante ao conceito de face já apresentado (uma imagem social positiva reclamada pelos interagentes). A negativa diz respeito ao que não se quer evidenciar, pois pertence ao território do eu (liberdade para agir e impor sem ser julgado). É importante pontuar que a face negativa se espelha na noção de território, proposta pela teoria goffmaniana.

Dessa forma, em uma interação, há pelo menos quatro faces envolvidas (positivas e negativas de locutores e interlocutores). Esse número é bem maior se considerarmos que os interagentes estão falando sobre alguém ou se o locutor fala para um auditório. Os dois casos são aplicáveis aos textos noticiosos veiculados pela mídia, que podem relatar algo sobre alguém para uma audiência significativa.

$\mathrm{Na}$ tentativa de preservar as faces envolvidas na interação (as suas e as dos outros) os interagentes, para Brown e Levinson (1987), adotam estratégias para amenizar as ameaças. Os autores, então, segundo Kerbrat-Orecchioni (2017), analisam os efeitos que os atos de fala têm, na interação, sobre as faces dos envolvidos e como esses atos se articulam com a cortesia. Existindo, todavia, dois tipos de face a serem preservadas/mantidas, Brown e Levinson defendem a existência de dois tipos de polidez, também negativa e positiva. A primeira é direcionada à preservação de faces negativas; e a segunda, à preservação de faces positivas. Além disso, os autores apresentam as modalidades bald-onrecord, on-record e off-record ${ }^{3}$, articuladas quando o locutor opta por realizar um ato ameaçador.

Devido ao papel de buscar informar a audiência acerca dos fatos, sem maiores comprometimentos da face do veículo midiático, a modalidade off-record é a que mais se faz presente na veiculação dos enunciados midiáticos. Isso, no entanto, não exclui a possibilidade de uso de estratégias bald-on-record e on-record. Assim, cabe destacarmos a possibilidade de que essas modalidades coexistam em uma interação. Em determinados enunciados, pode haver maior preocupação com a precisão da mensagem, sem preocupação com as faces - ao menos com a dos outros, sujeitos noticiados.

Soa-nos estranho, porém, a existência de uma "cortesia negativa", pois nos dá a ideia de algo inexistente, não verdadeiro, com valor, num sentido estrito, negativo. Sob esse olhar, uma cortesia negativa seria considerada, na verdade, uma descortesia. Encontramos em Kerbrat-Orecchioni (2006),

\footnotetext{
${ }^{3}$ Resumidamente, na modalidade bald-on-record, o locutor preza apenas pela precisão da mensagem, realizando o ato sem preocupação com a preservação das faces. Na on-record, o locutor demonstra comprometimento com o ato, realizandoo com atenção às faces envolvidas (suas e do interlocutor), adotando estratégias de polidez, preservando as faces envolvidas. Na off-record, o locutor opta por ser indireto, não se comprometendo ou não se envolvendo com o ato.
} 
todavia, uma releitura da teoria brownlevinsiana que defende que a polidez negativa não tem que ver, exclusivamente, com a preocupação com as faces negativas, mas sim em evitar ou atenuar a realização de FTAs (atos de ameaça à face), tanto para a face negativa como para a positiva do interlocutor. Ou seja, a cortesia negativa é, em sua essência, a não realização de uma descortesia, de um FTA, abster-se.

Já a cortesia positiva é a realização, dado seu caráter produtivo, de um ato anti-FTA, tanto para a face positiva como para a negativa do interlocutor. Kerbrat-Orecchioni nomeia esses "anti-FTA" de FFA (Face Flattering Acts - Atos lisonjeiros à face), que seriam o lado positivo dos FTAs, que tem, na verdade, o intuito de valorizar o outro, e não ameaçar, como os elogios, os agradecimentos, as felicitações etc.

Para a autora, a polidez é um conjunto de procedimentos utilizados pelos falantes para poupar ou valorizar o interlocutor e se traduz como norma, onde os FTAs são geralmente atenuados, suavizados (quando o conflito, por exemplo, não é o interesse da interação), enquanto os FFAs são intensificados, reforçados (como um agradecimento com "muito obrigado"). Buscamos, na tentativa de ser polido, enaltecer a face do outro, sempre que possível. Há, todavia, situações em que o objetivo de ser cortês concorre com objetivos diversos e concorrentes, como o de ser franco, preciso, sincero.

Quando essa concorrência está posta, mas não se tem pretensão de renunciar a nenhuma delas, há a necessidade de estabelecer um equilíbrio. Para Kerbrat-Orecchioni (2006), trata-se de situações de duplo vínculo, em que a harmonia entre eles é imprescindível para a concretização da polidez. Pautada pelo compromisso com a verdade, veiculada por meio de seus textos, e pelo respeito para com a audiência, a mídia precisa buscar formas de tentar estabelecer esse equilíbrio entre a precisão, a lisura, a veracidade do que é noticiado e a cortesia com os sujeitos envolvidos, bem como com o público, evitando FTAs.

Parece-nos mais coerente, sob um prisma prático, as noções estratégicas de FTA e FFA na articulação do fenômeno da cortesia. Considerar, como Brown e Levinson, que a cortesia gira apenas em torno de atos que ameaçam as faces seria o mesmo que dizer que vivemos em campos de tensão onde, até para se fazer um elogio ao outro, é preciso pensar como tal ato ameaçaria as faces. Admitimos, então, que é a perspectiva de cortesia proposta por Kerbrat-Orecchioni que nos filiamos majoritariamente, mas sem desconsiderar os apontamentos de Leech e Brown e Levinson.

Os FTA e os FFA não o são em todos os lugares e em todas as interações. Um ato compreendido como cortês na zona urbana, por exemplo, pode não o ser na zona rural. Há ainda a possibilidade de esse ato ser compreendido como não polido ${ }^{4}$. Em textos jornalísticos, cujo objetivo é, muitas vezes, denunciar,

\footnotetext{
${ }^{4}$ Sobre as possibilidades de articulação da polidez, os enunciados podem ser entendidos como: a) impolido: os interlocutores esperam ações de cortesia, mas elas não se efetivam na interação; b) polido: quando a cortesia esperada é efetivada ao longo da interação; c) não polido: quando não há expectativa de cortesia e ela de fato não ocorre; e d) hiperpolido: quando não há expectativa de cortesia na interação, mas ela acontece em exagero (LAKOFF, 1989; KERBRAT-ORECCHIONI, 2017). 
poderíamos conjecturar a predominância da não polidez. Contudo, devido à significância da audiência e o impacto sobre ela, o mínimo de cortesia é esperado e se faz necessário. Isso revela a importância de se considerar o contexto ao buscar interpretar os atos de cortesia. Não se espera de um jornal ou de qualquer veículo midiático atos descorteses; a cortesia também não poderá levar a uma hipervalorização do sujeito alvo da pauta, nem muito menos do veículo midiático e de seus operadores, jornalistas, comunicólogos etc. Assim, é preciso atenção para não confundirmos respeito e norma com cortesia, apesar de, em alguns casos, os dois estarem intimamente relacionados. A mesma perícia vale para os produtores dos textos.

\section{CONTEXTOS, SUJEITOS E INSTITUIÇÕES: NOVAS PERSPECTIVAS SOBRE O TRABALHO DE FACES}

É basilar ratificarmos a necessidade de que os diversos tipos de contextos, como os sociais, os culturais, os históricos, os ideológicos, os religiosos e os particulares, e os sujeitos envolvidos sejam considerados na análise da (des)cortesia e que, além disso, o enunciado só pode ser categorizado/significado, como considera Koike (2017), pelos outros, ou seja, a cortesia e a descortesia só são reconhecidas como tal pelos outros (ouvinte/interlocutor ou terceiros afetados pela enunciação). Se um texto pode ser entendido como descortês por um leitor, é porque há a possibilidade de tal interpretação.

Contudo, é preciso salientar a importância de que, em qualquer sociedade, por uma questão de poder e divisão de classes, algumas pessoas/instituições têm o "direito de ameaçar" as faces de outras, devido a posições que ocupam, sem que o ato seja considerado descortês ou impolido. É o caso, por exemplo, de um juiz ao proferir uma sentença; de um crítico ao analisar uma obra; etc. Para tais casos, é praticamente inevitável a realização de um FTA no exercício da atividade. No caso da mídia, todavia, essa "justificativa" é aceitável frente a uma causa maior: a função social de manter os cidadãos informados acerca do que se passa em sua comunidade, no país e no mundo.

Ocorre que, devido ao poder de propagação de suas mensagens, atos e discursos, os impactos dos FTAs realizados pela mídia podem ser devastadores para as imagens sociais dos sujeitos e para as instituições, já que muitos serão os "outros” receptores. Assim, apesar da concessão desse direito, essas ameaças podem ser realizadas adotando estratégias de polidez negativa, por meio da atenuação do FTA. Essa seria uma forma, inclusive, de preservar sua face como instituição séria, comprometida, respeitosa, beneficiando-se, portanto, de sua atitude cortês.

Esse benefício, que Leech (1983) propõe sempre existir, ao se optar por ser cortês, o que concordamos, é que faz com que defendamos a ideia de que toda cortesia é estratégica em algum grau, mesmo que ela aconteça sem o locutor planejar. Segundo Briz (2005), se é estrategicamente cortês quando se tem o objetivo diferente do de simplesmente ser cortês. Ora, se o único objetivo do falante é ser cortês, amplamente falando, seus atos serão dotados de estratégias que levem a esse objetivo de ser 
cortês, mesmo que desconsidere os benefícios de tal atitude. Diante disso, por considerar a cortesia como estratégica, dividimo-la em duas: a cortesia estratégica, para designar toda cortesia realizada com um objetivo explícito de se obter qualquer tipo de lucro, mesmo que mínimo; e, quando o locutor realizar a cortesia "simplesmente para ser cortês" (estratégia já beneficiaria sua face positiva), consideramos que há uma meta-cortesia estratégica, ou seja, a cortesia (linguística) usada para expressar meramente cortesia, apresentada em Rebouças (2018).

Entendendo a cortesia como uma estratégia para preservação das faces dos sujeitos, assumimos entendimento semelhante ao de Brown e Levinson nas noções de faces. Compreendemos que as faces podem ser definidas como imagens sociais (GOFFMAN, 2012), divididas em positivas (compostas de valores sociais positivos) e negativas (compostas por aspectos não positivos e não aprovados socialmente, e que, por isso, os sujeitos têm o desejo e o direito de não expor, de deixar no âmbito privado, não-público). Apoiamo-nos em Kerbrat-Orecchioni (2017), que apresenta uma distinção entre face individual e face coletiva (group face), para inferir e defender a existência de uma face institucional, já que uma instituição é formada por um grupo de pessoas que também têm faces.

As faces institucionais têm composições semelhantes às imagens positivas e negativas dos sujeitos, mas são mais complexas, já que são representadas, em alguns momentos, por sujeitos também dotados de faces, em um processo de mediação. Acreditamos que o conceito também seria aplicável a figuras públicas, que muitas vezes têm seus enunciados produzidos/veiculados por outros sujeitos. Os veículos jornalísticos, por exemplo, desejam manter determinada face perante seu público, como a de um veículo de credibilidade. Contudo, são as pessoas que trabalham na instituição, os jornalistas, principalmente, que produzirão enunciados que levem a tal imagem e trabalho de preservação das faces. Caso um profissional veicule uma notícia falsa, por exemplo, ameaçará não apenas suas faces positivas e negativas, mas também as do jornal, pois este atua como um “responsável maior" pelo que é enunciado.

Defendemos, portanto, que a face institucional não existe em si mesma. Ela é desenvolvida por meio de estratégias de trabalhos de faces de sujeitos envolvidos com essas instituições em contatos com outros sujeitos. Esses contatos podem se dar de diferentes formas: por um atendimento telefônico, por uma campanha publicitária e institucional, pela emissão de comunicados, pela divulgação de textos (o que revela o fato de que, além de mediado, o trabalho de face institucional é muitas vezes midiatizado). Kerbrat-Orecchioni (2017), ao apresentar o conceito de face grupal (que expandimos para face institucional), acrescenta que eventuais valorizações e desvalorizações de face de um dos indivíduos do grupo (ou da instituição) reflete em todo o grupo/comunidade. Por trás da articulação de uma face institucional e seus diversos momentos de interação, então, há pessoas (com suas faces) trabalhando.

Além disso, no caso de instituições constituídas, como empresas, governos ou ainda pessoas públicas, não podemos desconsiderar a existência de um plano de comunicação e de identidade, que trata 
de estratégias de preservação de marca. Esse manual não se limita à identidade visual, mas também contempla a imagem que a marca deseja ter diante da sociedade, as táticas a serem adotadas em casos de crise, o padrão de comunicação a ser seguido, dentre outras orientações. Finalmente, podemos definir face institucional como um valor positivo que instituições ou pessoas institucionalizadas buscam para si, por meio de práticas comunicacionais e discursivas que são planejadas estrategicamente antes das ações.

Nossa proposta é baseada em uma releitura dos estudos sobre a face. A proposta goffmaniana, datada de 1967, se nos apresenta pensada exclusivamente para a interação síncrona face a face. Contudo, o atual contexto social globalizado exige que novas considerações acerca do tema sejam tecidas. A comunicação sofreu transformações em decorrência do desenvolvimento de novas tecnologias que facilitaram a comunicação a distância. É o caso dos textos jornalísticos, que deixaram de ser divulgados exclusivamente em meios tradicionais. Nos ambientes digitais conectados à web, notícias são disponibilizadas a todo instante, disseminando-se com velocidade e ampliando o impacto e a audiência, por meio de compartilhamentos, comentários e reações valorativas (curtidas e marcações de admiração e repulsa), que se revelam como mecanismos de interação dos sujeitos com sua rede social, com o conteúdo e com as instituições, incluindo, mas não se limitando, as midiáticas.

Entendendo o trabalho de faces e a polidez como estratégicos, defendemos que há faces também em comunicações escritas, assíncronas e a distância. Em casos de enunciações públicas midiatizadas, como as notícias, os efeitos são redimensionados, pois mais sujeitos têm acesso aos enunciados, que podem tratar de outras instituições, pessoas, faces. Além disso, é necessária a consideração de que há uma instância produtora polifônica responsabilizada pelo dito, e que é dotada de histórias, reputação e interesses. Incumbidos por divulgar acontecimentos, os media noticiam sobre fatos, instituições e pessoas, devendo então desenvolver estratégias de trabalho de face. Quando disponibilizadas em ambientes digitais, o aspecto interativo se torna inegável, viabilizando, até para uma visão classicista, a existência/possibilidade de trabalho de face.

\section{ATENUAÇÃO E INTENSIFICAÇÃo COMO CAMINHOS DE ARTICULAÇÃo}

Apesar do rico trabalho de Brown e Levinson (1987), que nos apresentam estratégias para minimizar a força de um FTA, outros mecanismos podem ser utilizados com fins corteses e descorteses. É o caso da atenuação e da intensificação, recursos usados para marcar a intensidade do que dizemos. Ao pensarmos em atenuação, pensamos em um abrandamento do que é dito, em uma amenização dos efeitos de possíveis conflitos. Isso pode nos levar ao erro de pensar que atenuação e cortesia são sinônimos. Existe, de fato, uma atenuação cortês (BRIZ, 2014), contudo, o fenômeno é mais que isso.

A atenuação é uma categoria pragmática que pode ser percebida na cortesia como um mecanismo estratégico, logo intencional, utilizado para auxiliar o alcance do objetivo da interação (como a aceitação 
do interlocutor). Assim, o fenômeno só pode ser analisado considerando o contexto em que acontece (BRIZ, 2013; 2014). Também precisamos nos atentar às premissas do distanciamento e da proximidade entre os envolvidos (social ou funcional); do local mais ou menos cotidiano; da cotidianidade da temática discutida; e, por fim, dos objetivos interpessoais (da intenção no contato com o outro). Podemos inferir, então, que a atenuação é um recurso disponível ao locutor para negociar e diminuir a imposição do que é dito.

Por meio de estratégias de atenuação, o locutor reduz a relevância do dito, diminui a força ilocutiva do ato de fala. Pode haver, assim, um afastamento de eventuais ameaças às faces, já que o que se pretende enunciar não é feito de forma clara e direta. Podemos, então, relacionar a utilização de estratégias atenuadoras às máximas conversacionais de Grice. As máximas de quantidade, qualidade, relação e modo, às vezes, precisam não ser cumpridas, a fim de evitar eventuais ameaças. O locutor reduz a qualidade e a quantidade da informação para não soar descortês. Assim, a atenuação também pode se apresentar ao locutor para buscar não ser tão direto ou para evitar certos tópicos na interação.

Nas reflexões sobre cortesia, é comum encontrarmos a questão da atenuação. Fala-se em sua noção corriqueira de reduzir o efeito de um FTA. Contudo, é à proposta de Briz que nos alinhamos e realizamos novas reflexões. Para o autor, a estratégia atenuadora pode atuar em duas modalidades: uma linguística, em que há um efeito redutor sobre o que se diz ou fala, ou seja, um distanciamento da mensagem e de sua imposição, reduzindo o "peso" avaliativo da mensagem; e uma social, na qual a atenuação é utilizada - estrategicamente - pelo falante para proteger sua face e a do outro, podendo resultar em cortesia (BRIZ, 2005). Como estratégia interacional (SEARA, 2017), a atenuação pode evitar os conflitos e as tensões de uma interação, levando à preservação das faces dos sujeitos. Assim, mesmo em uma atenuação linguística, pode haver benefícios ou prejuízos às faces.

Em resumo, podemos afirmar que a atenuação não diz respeito apenas à mitigação ou à redução do valor do conteúdo. Trata-se de um recurso que os sujeitos utilizam, consciente e estrategicamente, para alcançar seus objetivos comunicacionais. Conforme os autores supracitados, a atenuação possibilita o distanciamento da mensagem, recurso comumente utilizado no jornalismo, por seu caráter "objetivo", mas também uma aproximação entre os interagentes, o que é interessante para a mídia, por inspirar maior confiança e credibilidade, assim como audiência. Essa preocupação com a forma como o recurso é utilizado e como ele pode levar à preservação das faces no jogo interacional envolve a manutenção e o reforço dos vínculos entre o veículo, a audiência e o conteúdo noticiado.

A modalidade da interação é outro fator importante. Textos escritos, formais, que pressupõem planejamento e mais tempo para desenvolvimento, são diferentes da comunicação oral, espontânea e não planejada. Assim, concordamos com Briz (2014) que a atenuação se faz mais presente em textos escritos, como os que pretendemos analisar, do que em interações face a face. Contudo, também cabe salientar 
que a suposta atenuação nos textos escritos pode não ocorrer, por não ter sido pretendida pelo locutor; o meio, ou ainda o gênero, por si só, não obriga a utilização de recursos ou práticas atenuadoras.

A própria dinâmica dessas modalidades (escrita e oral/face a face) dá consistência à observação de Briz. Em uma situação de fala simultânea, há "menos tempo" para evocar recursos atenuadores e, quando eles são utilizados, podem marcar um distanciamento entre os interagentes. Num diálogo entre irmãos, por exemplo, em que a preocupação com as faces dos envolvidos é menor, a existência de muitos recursos atenuadores, além de marcar um distanciamento entre os irmãos, poderia significar um excesso de (talvez falsa) cortesia e um tom irônico. Nos textos jornalísticos, todavia, pela busca da objetividade e da suposta "imparcialidade", esse distanciamento é necessário, assim como o trabalho de faces e da cortesia. Essas considerações evidenciam o caráter pragmático da estratégia de atenuação, pois, sem reconhecer a situação de comunicação, não se alcançariam tais entendimentos.

A atenção ao contexto interacional concreto faz Briz (2013; 2014) apontar três segmentos/elementos que interferem na atividade atenuadora e precisam ser observados: o elemento desencadeador, que é o membro do discurso que causa ou desencadeia a necessidade de se atenuar um ato (o contexto, por exemplo); o elemento atenuado, que seria o membro do discurso que é afetado pela atenuação, aquilo que é preciso atenuar (ação ou intenção); e o elemento atenuador, que é a expressão atenuadora propriamente dita e, caso esta exista, seu efeito. No caso do gênero notícia, o ato de noticiar e o propósito do texto são os desencadeadores da necessidade de atenuação. Já o fato noticiado pode ser o elemento atenuado, pois há casos de notícias em que as faces negativas estão/serão superexpostas.

Briz (2005) nos apresenta três tipos de atenuação e formas de articulação e alcance do objetivo atenuador. Atenuações estritamente pragmáticas são as que acontecem: pela própria ação atenuante do verbo performativo (que expressa ação, intenção ou ponto de vista); pela modificação do verbo performativo; por modificações modalizadoras "na margem"; pela elipse da conclusão; pela impessoalização do eu; e pela despersonalização do tu. Atenuações semântico-pragmáticas são as que acontecem: pela atenuação de um elemento por modificação gramatical ou léxica; pela atenuação de toda a proposição. Já as atenuações retóricas acontecem: quando elas expressam incerteza ou fingem ignorância ou incompetência diante do que é dito por outro interlocutor; quando elas manifestam, em movimentos concessivos-oposicionais ou restritivos, acordo/concordância parcial, mesmo com um desacordo preliminar (concordo com você, mas...); e quando elas impessoalizam o desacordo.

Podemos elencar, assim, alguns procedimentos utilizados na atenuação. Para redução do valor significativo, utilizamos minimizadores quantitativos, modalizadores, litotes e eufemismos; já para redução da força ilocutiva, utilizamos formas impessoalizadoras, expressões que incidem na objetividade do dito, distanciamento de generalizações, reparações de desconformidade, não apresentação de certeza, atribuição da responsabilidade do dito a outros etc. (ALBELDA MARCO; 
GARCÍA, 2013). Acrescentamos a esses recursos outras duas formas que podem levar à atenuação que dialogam: fuga do tópico (ou desfoque da temática) e foco no contexto da atenuação.

A fuga do tópico acontece quando o locutor evita introduzir na interação certas temáticas ou, caso isso não seja possível, realiza de forma imprecisa, e, se necessário, evoca informações ou atributos da face positiva dos interlocutores. $\mathrm{O}$ foco no contexto é um recurso que dialoga com o desfoque, por meio da não retomada de tópicos passados que podem interferir nas faces negativas, ou seja, o locutor opta por focalizar apenas o contexto, minimizando a referência a contextos e tópicos que trariam prejuízos às faces.

Em oposição, mas não em negação, à atenuação, temos a intensificação. Poderíamos pensar que se trata meramente da implantação de sufixos ou marcadores quantitativos, como: muito obrigado, espertíssimo, grandiosamente bela etc. Entretanto, diversas são as formas de articulação da intensificação. Para citar algumas possibilidades, o fenômeno pode ser notado como ênfase, expressividade, realce, ponderação, questão de grau, dentre outras (ALBELDA MARCO, 2005).

Apesar de a cortesia propor um abrandamento dos atos de ameaça a face, ou seja, ela estaria mais ligada a uma atenuação, há mecanismos ou estratégias intensificadoras que podem levar a enunciados corteses, ao menos na perspectiva de cortesia positiva proposta por Kerbrat-Orecchioni. Um muito preposto a um obrigado, por exemplo, intensifica o agradecimento e pode reafirmar a cortesia.

É com esse entendimento de que a cortesia pode ser alcançada tanto pela atenuação como pela intensificação que Albelda Marco (2005) desenvolve sua análise. Para a autora, a intensificação levaria a um aumento de obrigações, responsabilidade e aproximação da mensagem, enquanto a atenuação, a um distanciamento. Propondo, então, uma análise da intensificação a partir de um olhar pragmático, ela salienta a necessidade de se observarem os elementos utilizados na comunicação e a finalidade deles. É a partir desse olhar mais atento aos elementos verbais e não verbais que compõem as notícias veiculadas em portais que pretendemos desenvolver nossas reflexões.

Sendo a atenuação e a intensificação estratégias que podem ser utilizadas na comunicação para marcar uma avaliação, um posicionamento do emissor, tal recurso deveria ser usado com parcimônia em enunciados que se dizem imparciais, objetivos. Não é, todavia, o que percebemos. Podemos apreender que a mídia adota uma série de recursos linguísticos e visuais para assinalar juízos, como palavras e imagens destacadas, retomada de outros tópicos, galeria/histórico de fatos etc. Albelda Marco (2005) defende que são várias as formas linguísticas que o falante pode empregar para alcançar seus propósitos comunicativos. Pelas múltiplas possibilidades de agir com esses recursos, no plano da expressão, que só podem ser compreensíveis a partir do contexto, é que a autora defende a intensificação como categoria pragmática, entendimento que nos parece apropriado e alinhado às nossas perspectivas do fenômeno.

Podemos perceber que as tipologias da intensificação são, basicamente, duas, conforme Briz (2001) e Albelda Marco (2005): preposicional e modal. A primeira diz respeito à intensificação do 
dito, realizada por meio de uma modificação no âmbito semântico com uma marcação quantitativa. Já a intensificação modal envolve a modalidade, a atitude do locutor diante do conteúdo, dessa forma, esse tipo de intensificação interfere no dizer, com finalidades comunicativas.

Atenuação e intensificação se mostram, pois, como fenômenos complementares nas interações, distribuídos conforme os objetivos pragmáticos dos interagentes na situação de comunicação. Esses fenômenos podem atuar positiva e negativamente na comunicação, dependendo das estratégias ou das motivações do locutor, interferindo na modalidade, na polaridade e na qualidade do enunciado.

O dito tem sua verdade reforçada com os recursos de intensificação, que também modificam superlativamente a quantidade ou a qualidade da informação, além de influenciar na força ilocutiva (ALBELDA MARCO, 2007). Para isso, recorre-se a recursos morfológicos, sintáticos, léxicos e fonéticos, não se limitando a apenas um no enunciado. A intensificação pode ocorrer nos níveis: fônico, aumentando a intensidade; morfológico, com modificadores internos (prefixos e sufixos) e externos (como marcadores de quantidade); sintático, com repetições e consecutivos de intensidade; léxicosemântico, com expressões de intensidade, hipérbole e metáforas; de modalidade, interferindo no compromisso com a verdade ou com a certeza do que é dito (BRIZ; ALBELDA MARCO, 2013).

Há, ainda, a atuação no nível semântico-pragmático (quando a intensificação leva a significações mais positivas ou negativas) e a intensificação por elipse e por realce do papel dos interlocutores (BRIZ, 2001). O autor ainda menciona a possibilidade de a intensificação ocorrer através da manipulação do dito e do dizer, pelo reforço, pelo realce, pela ênfase e retomada e pelas inserções de informações.

Acreditamos no caráter avaliativo da atenuação e da intensificação, em seu caráter pragmático, e na diversidade das formas de atenuar e intensificar. Isso nos leva a defender uma categoria pragmático-imagética da atenuação e da intensificação, que envolve o juízo/avaliação que o locutor faz do conteúdo, articulado por meio desses mecanismos, mas que colabora para a criação de imagens do "conteúdo" abordado na e pela linguagem. Se "é na linguagem e pela linguagem que o homem se constitui como sujeito" (BENVENISTE, 2005, p. 286), também é nela e por meio dela que ele age, construindo imagens, atribuindo atributos às faces dos sujeitos e das instituições.

Inferimos que essa categoria pragmático-imagética é contextual, processual, e se desenvolve em um contínuo temporal. A intensificação e/ou a atenuação podem se apresentar com um significado pontual, no momento da enunciação, mas que leva à (re)formulação de imagens sociais positivas e negativas, a partir da replicação dos enunciados. Entendemos que esse recurso se faz muito presente na mídia, por exemplo, ao retomar informações muitas vezes desnecessárias que levam a ameaças e reforço das imagens positivas e negativas, mas também reforçam a avaliação. 
Nossa proposta de categoria abarca os mecanismos propostos por Briz (2005) e Albelda Marco (2005), que estão sendo discutidos neste trabalho, mas destacamos a necessidade de se considerarem a ênfase e o reforço do tópico, principalmente no caso dos textos midiáticos, por terem mais impacto e visibilidade e por poderem permanecer em pauta por um tempo maior que uma interação pontual. Com relação à ênfase, os textos podem reforçar sua avaliação sobre o dito, além do conteúdo proposicional propriamente, por meio de destaques na formatação no texto e de recursos imagéticos (que podem atenuar ou intensificar tanto imagens positivas como negativas). A ênfase também pode ser dada por meio da retomada de pontos específicos que acabam por reafirmar a avaliação que o locutor está fazendo do conteúdo.

A mídia tem a possibilidade, ainda, de retomar e reforçar os tópicos segundo seus interesses de pauta. Ela pode realizar retrospectivas, evocar fatos passados, reeditar textos, replicar e multiplicar conteúdos. Acreditamos que tais estratégias podem se desenvolver por meio da atenuação e da intensificação, ameaçando ou preservando as faces dos sujeitos e das instituições envolvidas, revelando, assim, a possibilidade de análise de um viés pragmático que impacta mais especificamente as faces.

\section{CONSIDERAÇÕES METODOLÓGICAS}

Esta pesquisa está inserida no campo da Pragmática Linguística, buscando observar o fenômeno da cortesia em textos jornalísticos, responsáveis por produzir diversos significados ao transcorrer a comunicação ordinária da sociedade. Por seu caráter cultural, e até particular, os estudos pragmáticos entendem a cortesia como estratégia discursiva. Dedicamo-nos a compreender, então, como os profissionais do jornalismo, no noticiário sobre corrupção, desenvolvem as marcas linguístico-discursivas do trabalho com as faces, valendo-se dos recursos de atenuação e de intensificação como estratégia para concepção de textos mais polidos.

O estudo é caracterizado como descritivo, com abordagem predominantemente qualitativa. Não pretendemos esgotar as possiblidades de interpretação dos implícitos, da memória discursiva dos veículos e até mesmo dos atos de ameaça à face. Interessa-nos o trabalho de faces direcionado aos protagonistas do acontecimento, contemplando as diferentes modalidades textuais e os diversos recursos visuais empregados pelos responsáveis pelos textos.

A descrição apresentada busca superar a mera identificação das relações entre as variáveis, dedicando-se também à determinação da natureza de tais relações. Ao buscar compreender os fenômenos contextualizados, a partir da linguagem em uso, ratificamos nosso compromisso com a perspectiva Pragmática da linguagem e com o empenho em evidenciar a relação da mídia com a vida cotidiana. 


\section{A condenação de lula: G1, Folha de S. Paulo e CartaCapital em análise}

Em nosso percurso analítico, debruçamo-nos sobre a cobertura jornalística que trata da condenação do ex-presidente Lula Inácio Lula da Silva, ocorrida em julho de 2017, pelo então juiz Sérgio Moro, veiculada em três portais de notícias brasileiros: G1, Folha de S. Paulo (Folha) e CartaCapital (Carta). Esclarecemos que a escolha de tais veículos não foi aleatória. O G1 foi escolhido por fazer parte do maior grupo de comunicação do país, o Grupo Globo, mas também por representar o portal de notícias da internet com maior audiência, com 52,8 milhões de visitantes únicos, contabilizando mais de 510 milhões de visualizações no portal. A Folha foi escolhida por ser o jornal líder em audiência na internet, com 32 milhões de usuários únicos e 190 milhões visualizações ${ }^{5}$.

O portal e a revista CartaCapital apresentam números mais tímidos. Segundo o Mídia Dados Brasil 2017, a Carta é a terceira maior revista semanal de atualidades, com mais 3 milhões de pessoas alcançadas pela versão digital. Em outubro de 2014, o portal alcançou quase 5 milhões de usuários, com mais de 10 milhões de visualizações às páginas do site da CartaCapital $^{6}$. O principal motivo, todavia, de esse portal compor nosso corpus de análise é o fato de sua postura declarar seu posicionamento político, como fez ao apoiar, em editorial de 20147 , apoio à reeleição de Dilma Rousseff à presidência da República.

G1 e Folha, diferentemente de Carta, posicionam-se, em seus manuais de princípios editoriais, como comprometidos com a isenção e o apartidarismo, apesar de reconhecerem, no caso do G1, a impossibilidade de apagamento da subjetividade do jornalista produtor do texto. Na produção, as marcas subjetivas devem ser apagadas ao máximo, focalizando o texto na "objetividade" do que é noticiado. Acreditamos que a escolha dos dois maiores portais de notícias na internet, somada a de um veículo de números menos expressivos, mas que se posiciona explicitamente, resulta em um corpus rico de estudo ${ }^{8}$.

Acerca da condenação/pauta em análise, é preciso destacarmos que, segundo a sentença, Lula foi condenado por ter recebido, através da doação de um tríplex pela empreiteira OAS, o valor equivalente a R \$2,4 milhões em propina. Ressaltamos ainda que não há provas documentais que atestem que o ex-presidente é o proprietário do imóvel. A condenação está baseada em uma suposta reserva do imóvel para Lula e em "anotações e rasuras em documentos apreendidos na casa de Lula", conforme consta na notícia do G1, que será analisada. Todas as reportagens são datadas de 12 de julho de 2017 e contam com atualizações na mesma data. Elas podem ser vistas na figura 1, que apresenta a manchete nos três veículos discutidos aqui.Figura 1 - Manchetes sobre a condenação de Lula em G1, Folha e Carta,

\section{respectivamente}

\footnotetext{
5 Dados disponibilizados em: <http://bit.ly/2YvTuaB> e <https://goo.gl/kf63Ro>. Acesso em 8 out. 2017.

6 Dados disponibilizados em: <https://goo.gl/mqRxHb>. Acesso em 8 out. 2017.

7 Editorial de 04/07/2014 disponível em: 〈http://bit.ly/2yqzYgY>. Acesso em 7 out. 2017.

8 Os princípios editoriais dos veículos também colaboraram para a escolha, como se verifica em Rebouças (2018).
} 


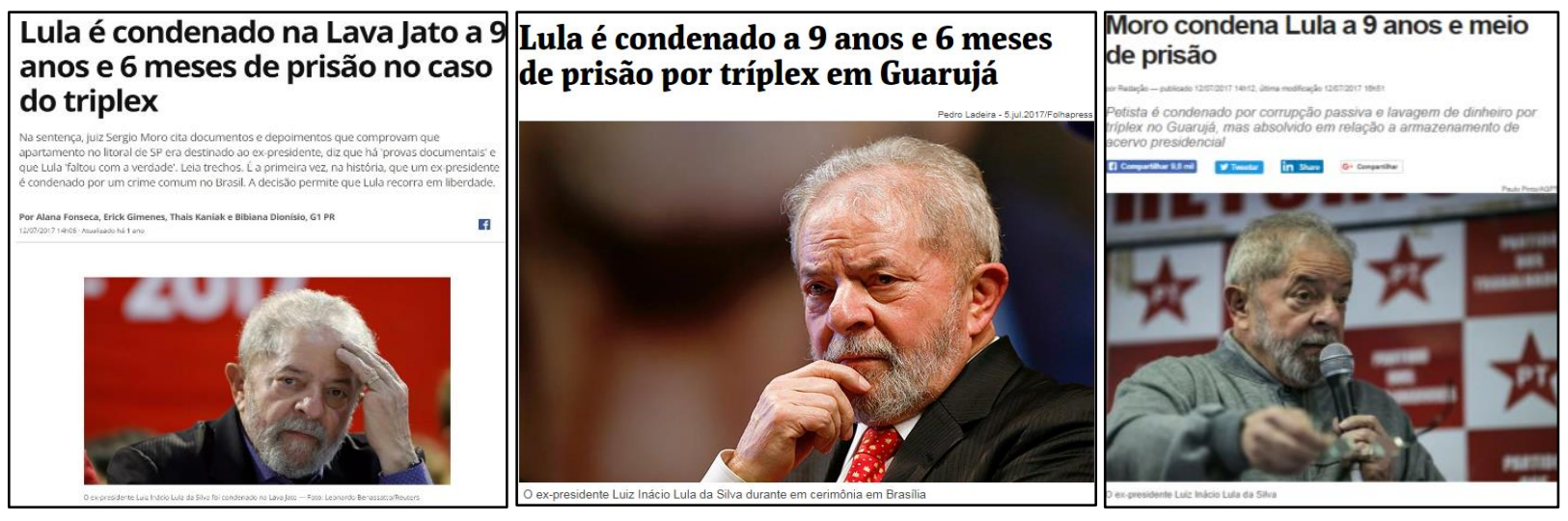

Fonte: G1, Folha de S. Paulo e CartaCapital, respectivamente, 12 jul. $2017^{9}$.

Como se observa, G1 apresenta sua cobertura sob a manchete "Lula é condenado na Lava Jato a 9 anos e 6 meses de prisão no caso do triplex". Compõem a parte inicial da enunciação a manchete, um texto auxiliar e uma imagem com legenda. Apesar de inferirmos que o leitor não dá à legenda da imagem a mesma atenção que dá ao texto principal, compreendemos que manchete, imagem, legenda e texto da notícia constituem um todo enunciativo e, por isso, também merecem olhar analítico.

É possível verificarmos na reportagem que, apesar do teor negativo do fato narrado, atenuações e intensificações se fazem presentes. $O$ recurso atenuador pode ser compreendido pela não explicitação do crime que levou à sentença. Menciona-se um triplex como suposta causa de condenação, mas apenas o leitor que possui certo conhecimento de mundo e do contexto social brasileiro conseguirá resgatar do que trata o texto, ao menos numa leitura limitada à manchete. O mesmo ocorre com relação ao âmbito da condenação. Sabe-se que uma lava-jato não é uma instituição legitimada para condenar alguém. Assim, é preciso que o leitor compreenda que o termo faz referência à denominação de uma operação realizada pela Polícia Federal. Ratificar que houve uma condenação à prisão, entretanto, intensifica o teor negativo do dito e pode ser compreendido como um ato descortês direcionado a Lula.

O texto auxiliar busca atrair a atenção do leitor, apresentando alguns detalhes sobre o que será encontrado no texto principal da reportagem. Os autores optam por apresentar um jogo de vozes, apropriando-se de trechos ditos por outros sujeitos. Compreendemos isso como uma estratégia que, ao passar a responsabilidade do dito para outro, preserva a face do G1. Contudo, ao final desse texto de destaque, os jornalistas e o veículo assumem a responsabilidade sobre o trecho "é a primeira vez que um ex-presidente é condenado por um crime comum no Brasil” e ameaçam as faces de Lula.

O texto imagético não aparece por acaso e não se apresenta como neutro. Pelo contrário: há uma intencionalidade nele e nos permite inferir alguns aspectos que levam a ameaças da face do expresidente. Como fundo composicional, há a predominância da cor vermelha, remetendo de forma

\footnotetext{
${ }^{9}$ As reportagens podem ser acessadas, na integra, nos seguintes endereços: <https://glo.bo/319eQbh>; <http://bit.ly/2Os76zL>; <http://bit.ly/2LX9TPF>. Todos os acessos datam de novembro de 2017. 
explícita, ao seu partido (PT). A imagem traz ainda Lula com a mão levada à cabeça, representando um sinal de preocupação. Nessa mesma mão, um detalhe pode chamar a atenção do interlocutor: a amputação de um dos dedos. Mesmo não o tendo impossibilitado de ser presidente do Brasil, esse aparente detalhe pode ter a intencionalidade de levar os leitores a uma percepção de fragilidade humana de ser imperfeito, incompleto, quando a imagem é percebida como um todo. Somados esses detalhes, aparentemente inexpressivos, a imagem exposta constitui um ato de ameaça à face e de descortesia.

Com a manchete "Lula é condenado a 9 anos e 6 meses de prisão por tríplex em Guarujá", a Folha apresenta sua cobertura e estabelece uma ameaça a todas as imagens sociais de Lula, pelo teor negativo do que é anunciado: a condenação à prisão. O motivo pelo qual ele é condenado não é claramente determinado, assim como no G1. O texto menciona um tríplex em Guarujá, mas também não explicita a qual crime a condenação é aplicada. Inferimos que a opção de não marcar, explicitamente, na manchete, o crime supostamente cometido, representa uma cortesia negativa com o uso da atenuação, preservando assim, mesmo que minimamente, alguns aspectos da imagem social de Lula, estratégia semelhante à adotada pelo G1. Segundo nossa proposta de categoria pragmático-imagética, trata-se de um recurso que, por meio da atenuação, não evoca uma marca (negativa) que acabaria por categorizar o sujeito, preservar uma imagem social, no caso analisado, a de Lula, principalmente. A face institucional da Folha, consequentemente, também acaba por ser preservada, pois o veículo não se coloca como instância julgadora, deixando de apontar, por exemplo, os fatos e os argumentos que sustentam a condenação.

A imagem que acompanha a reportagem vai de encontro à possível preservação identificada na manchete. Trata-se de imagem registrada alguns dias antes, onde Lula aparece em primeiro plano, cabisbaixo, com aparência triste e preocupada, e com a mão próxima à boca, indicando a imagem introspectiva de um pensador. Inferimos que tais características levam à atribuição de aspectos negativos à face de Lula, nesse contexto, por ser impossível desassociar o imagético do texto verbal.

Se, por exemplo, a imagem apresentada fosse uma em que Lula aparecesse com características tidas como positivas (sorrindo, mais descontraído, menos compenetrado), haveria uma atenuação do teor negativo da notícia, mantendo a face (negativa) preservada. Seria, sob nosso olhar, uma estratégia de cortesia negativa (na perspectiva de Kerbrat-Orecchioni [2006]), por evitar a intensificação de um FTA, inevitável à situação analisada. Contudo, o que percebemos na reportagem é uma intensificação da negatividade por meio da fotografia, que reforça se tratar de algo ruim (ser condenado). Nesse caso, tratase de um recurso visual, extralinguístico, para marcar a construção negativa da imagem de Lula, como feito na reportagem anterior. Há também uma imagem sombreada ao fundo, ambígua, podendo ser de um rosto em um plano bem maior. Uma sombra ou algo similar que se torna disforme.

Podemos verificar, ainda, que a legenda da imagem, ao categorizar Lula como ex-presidente e ao atrelar sua imagem às características mencionadas anteriormente, intensificando-as também ao 
mencionar o nome completo do sujeito, confere ênfase à face negativa. Inserir uma legenda como Lula em cerimônia em Brasília, apresentaria, sem prejuízo ao leitor, todas as informações necessárias até então. Com essa mesma legenda, mas associada a uma fotografia de características mais "positivas", poderia haver certo equilíbrio, preservando as faces do ex-presidente. Consideramos que nos elementos apresentados, através da atenuação e da intensificação, a Folha de S. Paulo, responsável pela veiculação da notícia, avalia o conteúdo apresentado. Os recursos empregados representam, ainda, uma forma de marcar positiva e negativamente a imagem do ex-presidente.

Seguimos nossa reflexão a partir da análise da reportagem publicada no site da CartaCapital, com autoria da redação, apresentada na manchete "Moro condena Lula a 9 anos e meio de prisão". É pertinente notarmos que a manchete da reportagem possui uma lógica de construção diferente da dos textos apresentados anteriormente. O título coloca Moro como sujeito da ação; e Lula como agente da passiva. Ao colocar o ex-presidente nesse papel, da pessoa que sofre o ato, podemos considerar que há uma tentativa de preservação de sua face, apesar da clara negatividade do fato.

Essa busca por manter certo equilíbrio entre ameaça e preservação da face de Lula também pode ser identificada na linha-fina. Apesar de fazer alusão ao Partido dos Trabalhadores e expor os crimes pelos quais o ex-presidente foi condenado, segue-se com a conjunção adversativa "mas", que acrescenta a informação da absolvição no caso de armazenamento de acervo presidencial. Percebemos, então, que a redação da CartaCapital busca enfocar não apenas os atos de fala que poderiam ameaçar as faces de Lula, promovendo equilíbrio entre pontos valorados negativa e positivamente, o que pode ser traduzido como busca por atitude de menor descortesia.

É possível identificar a presença desses contrapontos também na imagem. Vemos uma fotografia em que Lula está se dirigindo a um público, ocupando lugar de destaque provavelmente num palco e, portanto, controla os turnos de fala. Ao fundo, estrelas vermelhas com a sigla PT podem chamar a atenção do interlocutor. Essa composição nos leva a avaliar esse recurso imagético como relativamente "neutro".

Diferentemente das legendas apresentadas anteriormente, no site da Carta, o texto se limita a nomear a figura exposta na imagem. Apesar da presença do vocábulo "ex-presidente" e da utilização do nome completo de Lula, acreditamos não haver intensificação do valor negativo devido à "neutralidade" da imagem. Essa percepção pôde ser alcançada por considerarmos que os atos intensificadores e os atos atenuadores devem ser compreendidos como processos sempre contextuais e que dialogam entre si.

Ao longo do texto da reportagem, G1 e Folha possuem características semelhantes. Nos dois veículos, o ineditismo do caso (um ex-presidente condenado) é destacado e diferentes estratégias didatizadoras são aplicadas. São apresentados links para outras reportagens, vídeos explicativos, infográficos que detalham os fatos do processo e as penas de outros réus do caso, intensificando o valor negativo e a ameaça às faces dos envolvidos, principalmente em relação a Lula. Percebemos uma 
intensificação pelo realce, pelo uso das máximas da qualidade e quantidade (BRIZ, 2001; GRICE, 1982). Para os outros réus, porém, parece haver uma busca por preservação das faces negativas e por atenuação das ameaças, já que a menção a eles não é feita no início dos textos e não apresenta riqueza de detalhes.

Ainda é possível observar nesses dois portais uma atenção à preservação das faces do juiz do caso, Sérgio Moro, por meio de estratégias de polidez positiva (KERBRAT-ORECCHIONI, 2006). Esse tipo de atenção também é dado às faces institucionais dos próprios G1 e Folha, principalmente pela estratégia atenuadora de distanciamento do dito. Também podemos perceber esse "auto-trabalho" de face na Carta, o que não ocorre ao mencionar o juiz Sérgio Moro.

Ao tratar do motivo da condenação, a Carta o coloca como uma suposição. Se tivermos a condenação pelo recebimento de propina como fato, a opção da Carta por colocar o "benefício" como hipotético é entendida como ameaça à face de Moro. Pelo mesmo motivo, a face institucional do veículo também estaria sob ameaça, já que a audiência poderia questionar o porquê de o fato não ser tratado como dado. Contudo, os interlocutores que têm conhecimento do alinhamento político da Carta compreenderiam isso como um reforço editorial, logo, como uma preservação de sua face institucional.

Observações mais amplas, contemplando todo o texto das reportagens, podem ser apreciadas em trabalho anterior (REBOUÇAS, 2018), em que, além das reportagens sobre a condenação de Lula, são analisadas coberturas de outras personalidades políticas com abordagem comparativa. Aqui, detemonos a observações pontuais, a fim de viabilizar uma representação dos achados da pesquisa principal.

\section{CONSIDERAÇÕES FinAIS}

Tendo a problemática da "imparcialidade midiática" como pano de fundo latente, buscamos investigar, em textos noticiosos, como os profissionais do jornalismo desenvolvem as marcas linguísticodiscursivas do trabalho com as faces dos sujeitos protagonistas do noticiário sobre corrupção, com foco na cobertura da condenação do ex-presidente Lula em portais de notícias na internet, valendo-se dos recursos de atenuação e de intensificação como estratégia na concepção de enunciados mais corteses.

Identificamos uma clara realização de trabalho de faces por todos os veículos analisados, tanto com o objetivo de ameaçar como o de preservar. Acreditamos que, devido à natureza dos acontecimentos que nos propomos investigar, deparamo-nos com mais atos de ameaça do que de preservação. Esses últimos, direcionados, principalmente, às faces de instituições e dos próprios veículos de imprensa. Isso demonstra a necessidade de ampliação das discussões relacionadas ao conceito de face institucional, que introduzimos aqui. Sendo parte integrante da sociedade, as instituições precisam desenvolver suas comunicações sempre atentas aos impactos que suas imagens, suas faces, podem sofrer. Apesar de as instituições serem "abstratas", elas praticam ações e agem na sociedade através de pessoas. 
G1, Folha de S. Paulo e CartaCapital têm em comum a busca, ao menos em nosso corpus de análise, pela preservação de suas próprias faces. Essa característica já era algo esperado, dado o fato de parte da mídia hegemônica brasileira se considerar "imparcial” e apartidária, levando a um ideário de que a face de prestígio é construída através desses predicados. Sob esse prisma, pudemos perceber que a Carta é o veículo que, dado seu posicionamento explícito, mais expõe a sua face.

Em todos os textos, identificamos preservações e ameaças, cortesias e descortesias, atenuações e intensificações direcionadas aos diferentes personagens dos acontecimentos. As formas como esses fenômenos são construídos e interpretados são diversas e traduzem as intenções dos produtores, os posicionamentos editoriais e as questões econômicas e estruturais dos veículos. G1 e Folha, os que possuem as maiores audiências em nosso corpus, utilizam diversos recursos na construção textual (vídeos, links, imagens, infográficos, páginas exclusivas para certas coberturas), podendo despertar maior atenção dos coenunciadores. Já a Carta possui narrativas mais simplórias do ponto de vista midiático-visual (no corpus analisado, os únicos recursos empregados foram imagens e links, que é algo próprio da mídia digital). Além disso, G1 e Folha parecem ter um texto mais didático, facilitando a compreensão pelo público; já a Carta tem um texto que, em certos pontos, exige maior atenção do leitor.

Esses recursos da mídia digital permitem que os interagentes desenvolvam uma relação diferente com os conteúdos, interagindo com eles. Entretanto, observamos que os recursos também se fazem presentes como forma de atenuar ou de intensificar o que é dito, além de promover enunciados mais corteses ou descorteses, conforme detalharemos.

Acerca do caso da condenação de Lula, G1 e Folha utilizam estratégias semelhantes. Na manchete, podemos verificar atenuações e intensificações que levam a um inevitável ato descortês. Essa descortesia vai sendo praticada pelos veículos ao longo da reportagem de modos diferentes, valendo-se, principalmente, de recursos visuais, como a imagem apresentada logo no início do texto, que não valoriza atributos positivos do ex-presidente. G1 e Folha permitem ao leitor o aprofundamento sobre o caso através de diversos links com conteúdos de outros níveis, agregando, por meio dessa prática, predicados negativos à face de Lula. Em contrapartida, é evidente, conforme apresentamos em nossa análise, a presença de uma cortesia positiva direcionada ao juiz Sérgio Moro, buscando preservar suas faces, mas também as de instituições como o Supremo Tribunal Federal.

Por meio de um jogo de linguagem, a CartaCapital faz o oposto dos demais veículos. A reportagem sugere que há a pretensão não apenas de preservar as faces de Lula, mas também de valorála positivamente, desde a manchete e a escolha da imagem de apresentação. Já com relação a Moro, a Carta parece valorar negativamente (e politizar) as ações do juiz, colocando, inclusive, parte dos crimes cometidos por Lula (tidos pelo juiz como comprovados) como suposições. Contudo, faz isso mais diretamente em uma seção denominada "Os abusos de Moro". 


\section{REFERÊNCIAS}

ALBELDA MARCO, M. La intensificación en el español coloquial. 2004. 444f. Tese (Doutorado em Filologia) - Facultat de Filologia, Universitat de València, Valência, 2005.

ALBELDA MARCO, M. La intensificación como categoría pragmática: revisión y propuesta. Frankfurt: Peter, 2007.

ALBELDA MARCO, M.; GARCÍA, M. J. B. La cortesía en la comunicación. Madrid: Arco, 2013.

BENVENISTE, E. Problemas de Lingüística Geral. Campinas, SP: Pontes, 2005. v. 1.

BRIZ, A. El espanõl coloquial em la conversación: esbozo de pragmagramática. Barcelona: Ariel, 2001.

BRIZ, A. Atenuación y cortesía verbal en la conversación coloquial: su tratamiento en la clase de ELE. In: BRIZ, A. Actas del Programa de Formación del Profesorado de Español como Lengua Extranjera, Munique, p. 9-49, 2005, v. 2006. Disponível em: http://bit.ly/2Oxg2E0. Acesso em: 17 nov. 2017.

BRIZ, A. A atenuação e os atenuadores: estratégias e táticas. Tradução de Luiz Antônio da Silva, Adriana Marcelle de Andrade e Ramiro Carlos Caggiano Blanco. Linha D'Água, São Paulo, v. 26, n. 2, p. 281-314, 2013. Disponível em: http://bit.ly/314jbfV. Acesso em: 11 fev. 2018.

BRIZ, A. La atenuación lingüística: esbozo de una propuesta teórico-metodológica para su análisis. In: SEARA, I. R. (org.). Cortesia: olhares e (re)invenções. Lisboa: Chiado Editora, 2014. p. 89-144.

BRIZ, A.; ALBELDA, M. Una propuesta teórica y metodológica para el análisis de la atenuación lingüística en español y portugués. La base de un proyecto en común (ES. POR. ATENUACIÓN). Onomázein, n. 28, p. 288-319, 2013. Disponível em: http://bit.ly/2srjIg3. Acesso em: 12 fev. 2018.

BROWN, P.; LEVINSON, S. Politeness: some universals in language usage. Cambrige: University Press, 1987.

GOFFMAN, E. Ritual de interação: ensaios sobre o comportamento face a face. Petrópolis: Vozes, 2012.

GRICE, P. H. Lógica e Conversação. In: DASCAL.M. (org.). Fundamentos metodológicos da linguística: Problemas, críticas, perspectivas da linguística bibliográfica. Campinas: Unicamp, 1982. v. 4.

KERBRAT-ORECCHIONI, C. Análise da conversação: princípios e métodos. Tradução de Carlos Piovezani Filho. São Paulo: Parábola, 2006.

KERBRAT-ORECCHIONI, C. Abordagem intercultural da polidez linguística: problemas teóricos e estudo de caso. In: CABRAL, A. L. T.; SEARA, I. R.; GUARANHA, M. F. (org.). Descortesia e cortesia: expressão de culturas. São Paulo: Cortez, 2017.

KOIKE, D. A. Os frames culturais na fala: expectativas para a (des)cortesia. In: CABRAL, A. L. T.; SEARA, I. R.; GUARANHA, M. F. (org.). Descortesia e cortesia: expressão de culturas. São Paulo: Cortez, 2017.

LAKOFF, R. T. The limits of politeness: therapeutic and courtroom discourse. Multilingua, v. 8, n. 2-3, p. 101-130, 1989. Disponível em: https://goo.gl/3v9Gvo. Acesso em: 13 set. 2017. 
LAKOFF, R. T. The logic of politeness: Or, minding your p's and q's. In: CORUM, C.; SMITHSTARK, T. C.; WEISER, A. (org.). Papers from the 9th Regional Meeting of the Chicago Linguistic Society. Chicago: Chicago Linguistic Society, 1973.

LEECH, G. M. Principles of Pragmatics. London: Longman, 1983.

PAIVA, G. M. F.; MOREIRA, R. G.; SANTOS, L. A. P. F. Introdução aos Estudos de (Im)Polidez Linguística. Fortaleza: Centro Universitário Estácio do Ceará, 2016.

REBOUÇAS, D. M. (Des)cortesia em notícias sobre corrupção: atenuação e intensificação no trabalho com as faces. 2018. Dissertação (Mestrado em Linguística Aplicada) - Centro de Humanidades, Universidade Estadual do Ceará, Fortaleza, 2018.

SEARA, I. R. Contributo para o estudo da (des)cortesia: estratégias de atenuação e de intensificação nas interações. In: CABRAL, A. L. T.; SEARA, I. R.; GUARANHA, M. F. (org.) Descortesia e cortesia: expressão de culturas. São Paulo: Cortez, 2017.

SEARLE, R. J. Expressão e significado: estudo das teorias dos atos de fala. São Paulo: Martins Fontes, 2002. 